\title{
Metástases de coróide de origem testicular: relato de caso
}

\author{
Choroid metastasis of testicular primary site:case report
}

\author{
Marcos Rogério Mistro Piccinin ${ }^{1}$ \\ João Augusto de Almeida Jr. ${ }^{2}$ \\ Ricardo Dutra Aydos ${ }^{3}$ \\ Daniel Cruz Nogueira ${ }^{4}$ \\ Reinaldo Ferreira da Silva ${ }^{5}$
}

${ }^{1}$ Coordenador do Serviço de Oftalmologia do Hospital São Julião - Campo Grande (MS) - Brasil; Preceptor da Residência de Oftalmologia da Santa Casa de Campo Grande (MS) - Brasil.

2 Estagiário de Oftalmologia do Hospital São Julião Campo Grande (MS) - Brasil.

${ }^{3}$ Doutor em Cirurgia; Professor do Departamento de Clínica Cirúrgica da Universidade Federal de Mato Grosso do Sul - UFMS - Campo Grande (MS) - Brasil.

${ }^{4}$ Estagiário de Oftalmologia do Hospital São Julião Campo Grande (MS) - Brasil.

${ }^{5}$ Estagiário de Oftalmologia do Hospital São Julião Campo Grande (MS) - Brasil.

Endereço para correspondência: Marcos Rogério M Piccinin. Rua 15 de Novembro, 574 - Campo Grande (MS) CEP 70002-140

E-mail: mrpiccinin@yahoo.com.br

Recebido para publicação em 26.09.2005

Última versão recebida em 09.02.2006

Aprovação em 05.03.2006

Nota Editorial: Depois de concluída a análise do artigo sob sigilo editorial e com a anuência da Dra. Vera

Regina Cardoso Castanhreira sobre a divulgação de seu nome como revisora, agradecemos sua participação neste processo.

\section{RESUMO}

Descrição do caso de um paciente masculino de 22 anos de idade, cor parda, com decréscimo da acuidade visual em olho esquerdo e com diagnóstico de tumor testicular e metástases para pulmão e rim. Avaliação da evolução da lesão coroideana compatível com metástase ocular de tumor testicular por meio de exame oftalmológico e ecográfico. Houve resolução da lesão intra-ocular juntamente com melhora radiológica pulmonar após quimioterapia durante aproximadamente 4 meses de acompanhamento. Apesar da remissão da lesão ocular, o paciente faleceu por complicações decorrentes de metástase cerebral. Abordada na literatura como rara, não foi encontrado qualquer relato de caso sobre a metástase de coróide com sítio testicular, sendo esta, talvez, sua primeira descrição.

Descritores: Neoplasias da coróide/secundário; Neoplasias testiculares; Metástase neoplásica

\section{INTRODUCÃO}

Antigamente considerado raro, o câncer metastático para o olho é atualmente reconhecido como o processo maligno ocular mais freqüente na vida adulta, com uma incidência que supera a do melanoma de coróide ${ }^{(1-3)}$.

Geralmente, é um carcinoma que invade a coróide de um ou ambos os olhos, levando com freqüência ao descolamento de retina exsudativo com comprometimento visual, que determina, muitas vezes, o diagnóstico antes da descoberta do sítio primário. Sabe-se que ao redor de $10 \%$ das portadoras de câncer de mama e mais de $50 \%$ dos casos de câncer de pulmão ou de rim terão lesão ocular observadas antes do diagnóstico clínico e poderão ser tratadas como uveíte sem ao menos ser lembrada como sendo metástase coroideana $^{(1-5)}$.

Até o momento, o diagnóstico de tumores da coróide são baseados principalmente na oftalmoscopia e ecografia ${ }^{(5-6)}$. Mas, outros exames como a angiografia ${ }^{(6)}$ e o citológico de fluido sub-retiniano podem ser úteis no diagnóstico diferencial ${ }^{(5)}$.

O prognóstico visual em curto prazo é usualmente bom após uma terapêutica individualizada, mas o prognóstico sistêmico é ruim para pacientes com metástases intra-oculares ${ }^{(1-3,5,7)}$.

\section{RELATO DE CASO}

Paciente masculino, 22 anos, cor parda, estudante, natural de Presidente Prudente - SP e procedente de Campo Grande - MS, procurou o Serviço de Oftalmologia do Hospital São Julião em 24/08/2002, com queixa de embaçamento visual de olho esquerdo há 2 semanas. Ao exame oftalmológico foi constatado acuidade visual $(\mathrm{AV})$ de $\mathrm{OD}=20 / 80$ e $\mathrm{OE}=20 / 200$; tonometria de 
$14 \mathrm{mmHg}$ em ambos os olhos (AO); ectoscopia, motilidade ocular e biomicroscopia de segmento anterior normal em AO; biomicroscopia de fundo $\mathrm{OD}=$ estruturas sem alterações e $\mathrm{OE}=$ presença de importante opacidade vítrea (Tyndall 3+/4+) com lesão elevada de coloração esbranquiçada na região da retina nasal com prejuízo na definição de detalhes por opacidade dos meios transparentes. Levantou-se hipótese diagnóstica de uveíte posterior ou infiltração neoplásica da coróide de OE. Após o exame, interrogou-se novamente o paciente sobre a existência de patologias sistêmicas e o mesmo relatou que estava em tratamento quimioterápico para tumor de testículo. Foi solicitado laudo e exames complementares sobre quadro sistêmico.

No mesmo dia foram realizadas retinografias e ecografia de OE que mostrou lesão elevada de $5 \mathrm{~mm}$ em setor nasal de globo ocular, de alta refletividade e consistência ecográfica homogênea em seu interior; cavidade vítrea com picos difusos de baixa refletividade e ampla mobilidade; retina aplicada e cristalino tópico (Figura 1).

Paciente retornou em 15 dias (09/09) com resultado de exames complementares: 1) Exame anátomo-patológico de lesão de testículo esquerdo compatível com tumor de linhagem germinativa mista; 2) Imuno-histoquímica revelando tumor com predomínio de um teratoma maturo e imaturo ao lado de diferenciação seminomatosa e coriocarcinoma; 3) Raios-X de tórax demonstrando múltiplos nódulos em ambos os pulmões; 4) Tomografia computadorizada (TC) e ecografia de abdômen mostrando nódulo renal; 5) TC de crânio normal. Foi realizada nova ecografia ocular que mostrou lesão semelhante ao exame inicial $(4,7 \mathrm{~mm})$. O paciente havia realizado a $2^{\underline{q}}$ sessão de quimioterapia há 4 dias.

No dia 24/09, o paciente retornou referindo melhora da visão
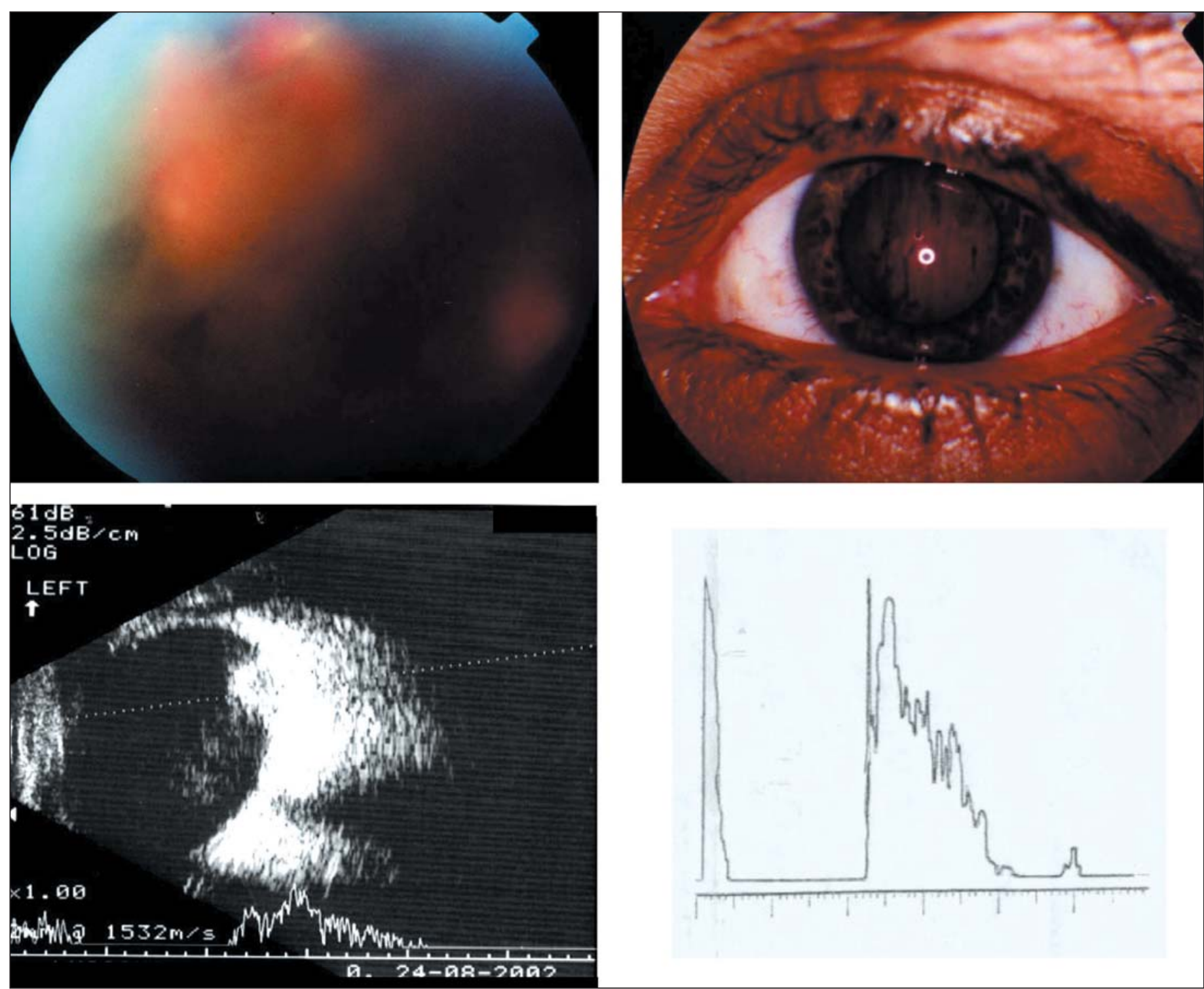

Figura 1 - Imagens retinográfica, biomicroscópica e ecográfica, modos B e A, de lesão ocular esquerda 
$(\mathrm{OE}=20 / 100)$. O exame ecográfico do OE demonstrou diminuição da lesão $(2,8 \mathrm{~mm})$, porém persistia com turvação vítrea (Figura 2). O quadro encontrava-se inalterado no dia 08/10, porém no dia 22/10 a ecografia do OE demonstrou diminuição importante da lesão $(<1 \mathrm{~mm})$ e persistência da turvação vítrea.

No dia 12/11, o paciente trouxe raio-X de tórax mostrando redução importante das lesões pulmonares. Ao exame oftalmológico verificamos acuidade visual de 20/60 no OE e melhora da opacidade vítrea (Tyndall $2+$ ). Na biomicroscopia de fundo observou-se lesão plana, esbranquiçada, sub-retiniana com aspecto de tecido fibroso em região nasal do globo ocular (Figura 3). A ecografia mostrou ecos vítreos de baixa refletividade e ampla mobilidade, retina aplicada e desaparecimento da lesão no setor nasal do OE (Figura 4). Nesta mesma época houve também melhora sistêmica.

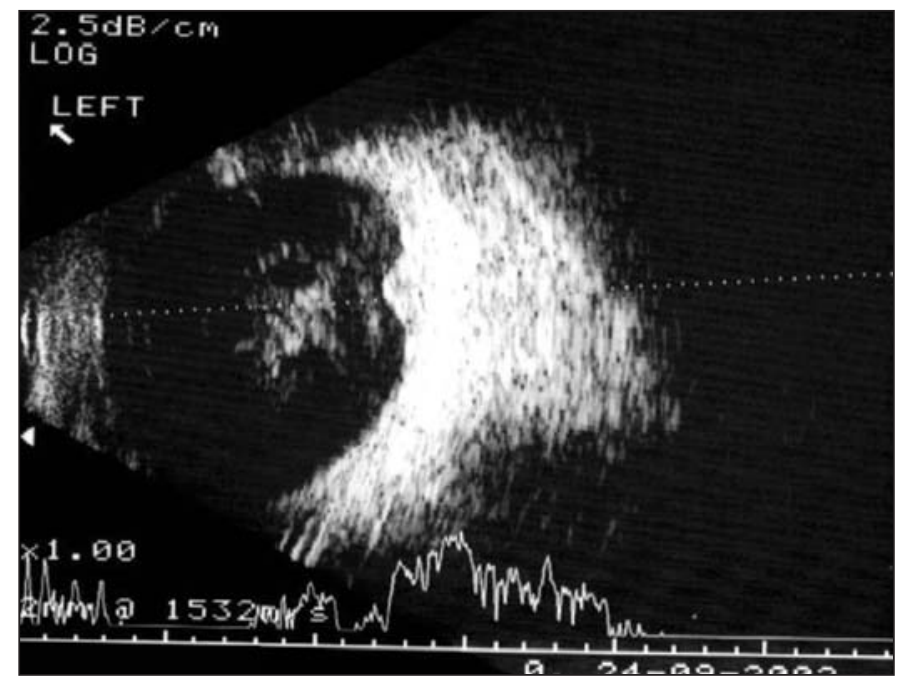

Figura 2 - Imagem ecográfica após 1 mês de evolução

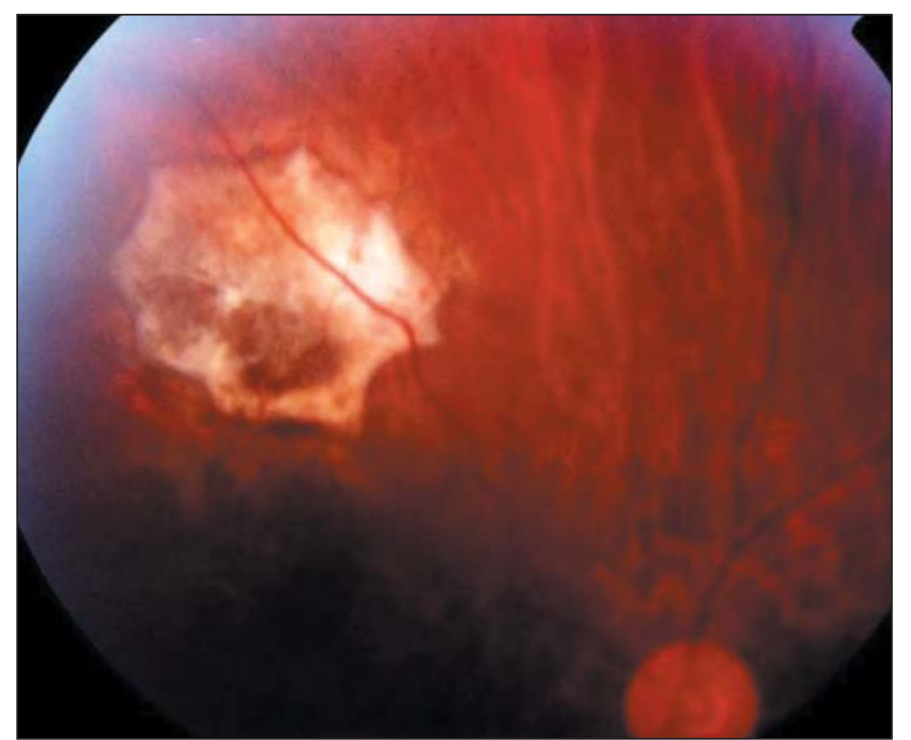

Figura 3 - Imagem retinográfica de lesão cicatricial remanescente
No dia 17/12, o paciente retornou referindo que a visão estava boa, porém vinha apresentando crises convulsivas. Ao exame oftalmológico verificamos acuidade visual com correção de $\mathrm{OD}=20 / 20$ e OE=20/30. Na biomicroscopia de fundo observamos leve opacidade vítrea e lesão cicatricial em retina nasal. No dia 21/01, o paciente continuava sem sintomas oculares, mas queixava-se de cefaléia intensa.

Em fevereiro ficamos sabendo que o paciente estava internado na UTI de outro hospital e que seria submetido à cirurgia neurológica para retirada de nódulo tumoral encefálico. Alguns dias após a cirurgia, o paciente foi a óbito por complicações pós-operatórias.

\section{DISCUSSÃO}

O câncer pode afetar o olho e a órbita como resultado direto de infiltração metastática, deslocamento do globo ocular, compressão do nervo óptico ou anticorpos circulantes envolvendo degeneração paraneoplásica da retina. Um tumor metastático para a úvea é a forma mais comum de um processo metastático intra-ocular, sendo a coróide o sítio mais comum, enquanto corpo ciliar, íris, retina, disco óptico e vítreo são sítios $\operatorname{raros}^{(2)}$.

Aproximadamente um terço dos pacientes não têm história de câncer primário quando do diagnóstico de tumor ocular, principalmente nos casos de neoplasia de origem pulmonar e renal $^{(1-3)}$. Os locais primários mais frequientes são a mama em mulheres e o pulmão em homens, enquanto os menos comuns são os rins, trato gastrointestinal, próstata e testículo, sendo o último, o motivo do relato de caso em questão ${ }^{(1-3,5,7-8)}$.

\section{Características dos tumores de testículo}

São tumores raros, representando cerca de $1 \%$ de todos os cânceres no homem, mais comuns em brancos que em negros, com incidência anual de 6/100.000 homens, sendo o processo

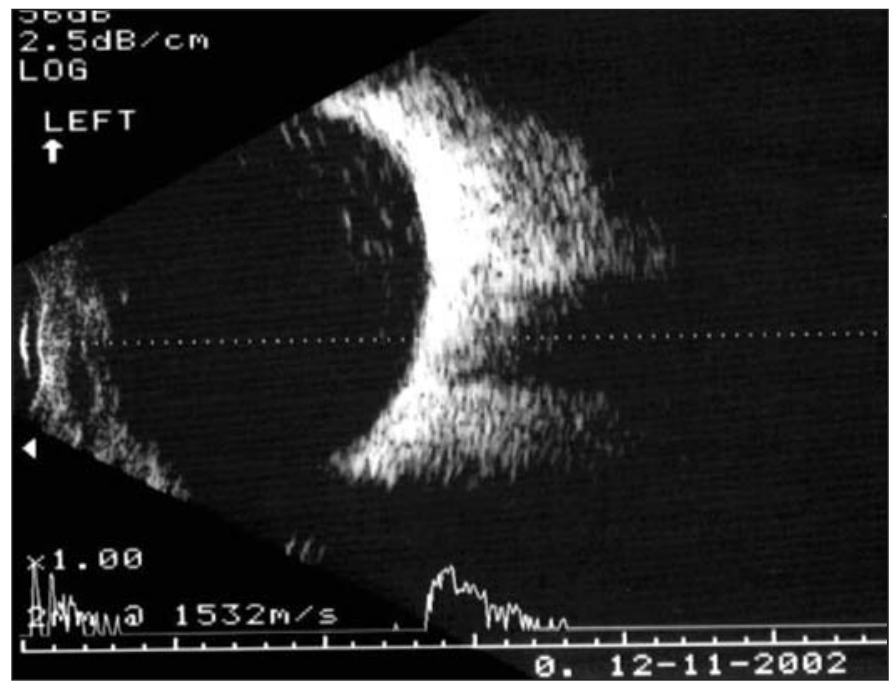

Figura 4 - Imagem ecográfica após resolução da lesão ocular 
maligno mais comum na faixa etária de 20 a 35 anos. O principal fator de risco é o criptorquidismo ${ }^{(3)}$.

Cerca de $95 \%$ dos tumores de testículo são malignos e derivados de células germinativas, já os $5 \%$ restantes são nãogerminativos e, amiúde, benignos. Os cânceres de células germinativas são classificados em seminomas e não-seminomas. Os não-seminomas incluem carcinomas de células embrionárias, coriocarcinomas e teratomas. Quarenta por cento dos cânceres de células germinativas contêm uma mistura de elementos seminomatosos e não-seminomatosos e a existência de qualquer elemento não-seminomatoso o classifica como tal ${ }^{(3)}$.

A diferenciação entre seminoma e não-seminoma e seus estágios é importante para a terapia subseqüente ${ }^{(9)}$. Os seminomas metastizam via linfática para os linfonodos regionais, retroperitoneais, mediastinais e supra-claviculares, sendo muito sensíveis à radioterapia ${ }^{(3,10-12)}$. Por outro lado, os não-seminomas metastizam por vias linfáticas e hematogênicas (em especial para fígado e pulmões), sendo radiorresistentes ${ }^{(3)}$.

Em nosso caso tem-se exatamente a associação de seminoma com teratoma e coriocarcinoma, classificando-o como um tumor não-seminomatoso. Essa classificação foi possível, devido ao quadro morfológico do anátomo-patológico e à análise imuno-histoquímica com positividade para os marcadores PLAP, gonadotropina coriônica humana (HCG) e antígenos embrionários (AE1/AE3).

Os tumores de células germinativas, principalmente os nãoseminomas, secretam marcadores biológicos utilizados para monitorar a resposta terapêutica, como por exemplo, a alfafetoproteína secretada pelos carcinomas de células embrionárias e a HCG secretada por todos os coriocarcinomas e um terço dos carcinomas de células embrionárias e teratomas ${ }^{(3,13-14)}$.

\section{Características da metástase para a coróide}

O tumor metastático intra-ocular é uma neoplasia maligna que se propaga por via hematogênica para o trato uveal, retina, disco óptico, ou outras estruturas oculares ${ }^{(1-5)}$. Historicamente era considerada uma doença rara, sendo que em 1944, Cordes relatou que poucos oftalmologistas tinham visto sequer um único caso. Contudo, hoje, sabe-se que o tumor metastático para a úvea é a forma mais comum de neoplasia maligna intra-ocular. Muitos casos não são diagnosticados, pois o exame oftalmológico não é realizado de rotina em pacientes com metástases e extremamente doentes ${ }^{(1)}$.

A metástase tumoral para a úvea ocorre tipicamente em pacientes de meia-idade ou idosos (dos 40 aos 70 anos) e, com exceção dos processos leucêmicos, é rara em crianças ${ }^{(1)}$.

Os achados clínicos variam com a localização do tumor intra-ocular, podendo o paciente com metátases para a coróide ser assintomático ou apresentar baixa acuidade visual sem dor. Em poucos casos, pode manifestar-se inicialmente com dor causada por um glaucoma secundário ${ }^{(1-3,5)}$.

A maioria das metátases intra-oculares são os carcinomas, sendo raros os sarcomas e os melanomas malignos ${ }^{(1)}$.

A disseminação tumoral para o olho ocorre principalmente por via hematogênica, devido a ausência de vasos linfáticos e ampla vascularização coroidiana ${ }^{(1,5)}$. Embora a metástase coroidal possa ocorrer em todo o fundo de olho, ela tem predileção pelo pólo posterior, apresentando-se usualmente com comprometimento visual em um ou ambos os olhos e, ocasionalmente, invade o nervo óptico e causa grande baixa de visão ${ }^{(2,4-5,15-16)}$. O exame oftalmoscópico revela freqüentemente uma lesão em placa amarelada, pouco elevada e homogênea, apresentando descolamento seroso da retina e alterações do epitélio pigmentar da retina. Ocasionalmente, as lesões são multinodulares, elevadas e apresentam depósito de pigmento no seu interior simulando lesões melanóticas ${ }^{(1,4-5)}$.

$\mathrm{O}$ descolamento seroso da retina sensorial pode acometer até $75 \%$ dos casos, podendo a região macular ser comprometida quando adjacente ao tumor. Em raros casos, o descolamento pode ser bolhoso e extenso ${ }^{(1)}$.

As metástases coroideanas produzem também descolamentos periféricos da coróide, simulando síndrome de efusão uveal, particularmente quando o tumor primário é de pulmão. Raramente esses tumores assumem forma de cogumelo, quando parte da lesão torna-se sub-retiniana pela ruptura da membrana de Bruch, como é característico no melanoma primário da úvea de moderada a grandes dimensões ${ }^{(1,4-5)}$.

Várias entidades clínicas simulam uma metástase coroideana e devem ser consideradas no diagnóstico diferencial, como nevus amelanótico, melanoma amelanótico, hemangioma da coróide, esclerite posterior, osteoma da coróide, retinites e coroidites, descolamentos retinianos regmatogênicos, doença de Harada, síndrome de efusão uveal, e coriorretinopatia serosa central ${ }^{(1)}$.

No caso descrito, a acuidade visual baixa do olho esquerdo e a presença de lesão ocular de aspecto morfológico tumoral (solitária, esbranquiçada, não-pigmentada, elevada e de bordas mal definidas), associados à história de um sítio tumoral primário testicular, levaram-nos a suspeitar de um tumor metastático ocular; suspeita essa que ficou mais evidente com o desaparecimento do tumor ocular e a melhora significativa da acuidade visual (20/200 para 20/30 no olho afetado) durante o tratamento quimioterápico.

Alguns exames complementares são importantes no diagnóstico como: angiografia fluoresceínica, ecografia, tomografia computadorizada, ressonância magnética nuclear e, eventualmente, a biópsia por aspiração com agulha fina ou em cunha, nos casos em que não se localizou o tumor primário ou há suspeita de uma segunda neoplasia, porém a biopsia deve ser aventada com cautela, pois a conduta é controversa ${ }^{(1,5-6)}$.

Apesar da angiografia mostrar padrões variáveis ${ }^{(5-6)}$, ela pode ser útil no diagnóstico diferencial pelo bloqueio do contraste e detecção ou não de vasos intratumorais ${ }^{(6)}$. Em contraste com o hemangioma e o melanoma, muitos carcinomas metástaticos são hipofluorescentes nas fases arterial e venosa precoce e hiperfluorescentes nas fases subseqüentes. Contudo, algumas vezes tais tumores podem hiperfluorescer precocemente ${ }^{(1,5-6)}$. No caso em questão, não foi possível a realização da angiografia por turvação vítrea. 
A ecografia é útil no diagnóstico das metástases coroideanas, principalmente se existem opacidades dos meios ópticos ou descolamento de retina bolhoso que dificultam o exame do fundo de olho. Os carcinomas metastáticos apresentam-se como uma elevação discreta a moderada, embora ocasionalmente sejam completamente elevados. Mostram-se tipicamente irregulares e com freqüência se escavam em sua porção central. Possuem refletividade interna de média a alta e irregular, com vários picos de refletividade. A vascularização interna é mínima ou ausente e observa-se que o descolamento seroso da retina tende a ser mais elevado e extenso que o encontrado no melanoma ${ }^{(1,5)}$.

O tratamento para a metástase intra-ocular varia da simples observação até a ressecção cirúrgica, dependendo da agressividade, localização e extensão do tumor, dos sintomas, do grau de controle quimioterápico, resposta à radioterapia e do sítio primário ${ }^{(1,3,5,7)}$.

Alguns tumores metastáticos para a coróide são inativos ou não requerem tratamento ocular específico, regredindo após o tratamento do tumor primário ${ }^{(1,3,5,7)}$.

O paciente deve ser acompanhado a intervalos de 2 a 4 meses com realização de exame oftalmológico completo e ecografia ocular para avaliação morfológica do tumor e pesquisa de descolamento da retina secundário, que usualmente requer tratamento mais ativo ${ }^{(1)}$.

A radioterapia é necessária se o paciente tem baixa acuidade visual por envolvimento macular e, no geral, é muito efetiva para o controle do tumor, que pode ser acompanhado pela diminuição do tamanho do mesmo, desaparecimento do descolamento retiniano e proliferação do epitélio pigmentar da retina. A acuidade visual freqüentemente mostra uma grande melhora nos pacientes com sucesso terapêutico ${ }^{(1,7)}$.

A enucleação ou excisão cirúrgica local do tumor metastático é justificada em alguns casos de crescimento incontrolável e de dor por glaucoma secundário associados a importante baixa de visão ${ }^{(1,3,5)}$.

No geral, o prognóstico de vida para os pacientes com tumores metastáticos intra-oculares é muito pobre, sendo a média de sobrevida após o diagnóstico de 3 a 5 meses nos casos de tumores pulmonares e de 8 a 12 meses nos tumores de mama. No caso relatado, o paciente faleceu por complicações decorrentes do tratamento de metástase cerebral, a despeito da melhora ocular.

\section{AGRADECIMENTOS}

Agradecemos aos colegas Klissia Pires Souza Piccinin, Cleiton Cassio Bach e Paulo Arian Conciani pelos auxílios prestados na elaboração desse relato de caso.

\section{ABSTRACT}

Description of a male patient case, 22 years old, presenting visual acuity decrease in the left eye associated with the diagnosis of metastatic testicular tumor to lung and kidney. Evaluation of the evolution of a choroid lesion compatible with ocular metastasis of testis tumor through ophthalmologic and echographic examinations. There was resolution of the intraocular lesion together with lung radiologic improvement after chemotherapy during approximately 4 months of follow-up. In spite of the remission of the ocular lesion, the patient died due to complications of cerebral metastasis. Approached in the literature as rare, no report was found of a case of choroidal metastasis of a testicular site, this being, perhaps, its first description.

Keywords: Choroid neoplasms/secondary; Testicular neoplasms; Neoplasm metastasis

\section{REFERÊNCIAS}

1. Castro E, Vianna RNG, Ávila M. Metástases intra-oculares. In: Abujamra S, Ávila M, Barsante C, Farah ME, Gonçalves JOR, Lavinsky J, et al. Retina e vítreo: clínica e cirurgia. São Paulo: Roca; 2000. p.398-402.

2. De Potter P, Disneur D, Levecq L, Snyers B. [Ocular manifestations of cancer]. J Fr Ophtalmol. 2002;25(2):194-202. French.

3. Matsumoto AM. Doenças endócrinas masculinas: os testículos. In: Wyngaarden JB, Smith LH, Bennett JC, editores. Cecil: tratado de medicina interna. 20 ed. Rio de Janeiro: Guanabara Koogan; 1997. p.1483, p.2406.

4. Schocket LS, Syed NA, Fine SL. Primary adrenal lymphoma with choroidal metastases. Am J Ophthalmol. 2002;134(5):775-6.

5. Kanski JJ. Clinical ophthalmology. A systematic approach. 3rd ed. Oxford: Butterworth-Heinemann; 1994. p.219-21.

6. Krause L, Bechrakis NE, Kreusel KM, Servetopoulou F, Heinrich S, Foerster $\mathrm{MH}$. [Indocyanine green angiography in choroid metastases]. Ophthalmologe. 2002;99(8):617-9. German

7. Weigel T, Bottke D, Kreusel KM, Schmidt S, Bornfeld N, Foerster MH, Hinkelbein W. German Cancer Society. External beam radiotherapy of choroidal metastases - final results of a propective study of the German Cancer Society (ARO 95-08). Radiother Oncol. 2002;64(1):13-8.

8. Gupta M, Puri P, Jacques R, Rennie IG. Retinochoroidal mass: a presenting feature of metastatic oat cell carcinoma of lung. Eur J Ophthalmol. 2002;12 (6):550-2.

9. Nichols CR. Testicular cancer. Curr Probl Cancer. 1998;22(4):187-274.

10. Porcaro AB, Antoniolli SZ, Schiavone D, Maffei N, Bassetto MA, Curti P. Management of clinical stage I testicular pure seminoma. Report on 42 patients and review of the literature. Arch Ital Urol Androl. 2002;74(2):77-80.

11. Livsey JE, Taylor B, Mobarek N, Cooper RA, Carrington B, Logue JP. Patterns of relapse following radiotherapy for stage I seminoma of the testis: implications for follow-up. Clin Oncol (R Coll Radiol). 2001;13(4):296-300.

12. Foster RS. Secondary tumors after initial successful treatment of metastatic testis cancer. Curr Opin Urol. 1999;9(5):443-5.

13. Bompas E, Fléchon A, Biron P, Droz JP. [Management of advanced seminoma: retrospective study of 96 patients]. Bull Cancer. 2002;89(10):877-85. French.

14. Stenning SP, Parkinson MC, Fisher C, Mead GM, Cook PA, Fossa SD, et al. Postchemotherapy residual masses in germ cell tumor patients: content, clinical features, and prognosis. Medical Research Council Testicular Tumour Working Party. Cancer. 1998;83(7):1409-19.

15. Finger PT, Warren FA, Gelman YP, McCormick SA. Adult Wilms' tumor metastatic to the choroid of the eye. Ophthalmology. 2002;109(11):2134-6.

16. Biswas J, Krishnakumar S, Bhavsar K, Shanmugam MP. Choroidal metastasis of a gingival squamous cell carcinoma. Am J Ophthalmol. 2002;133(5): 713-5. 